\title{
O fazer coletivo nas políticas de saúde da Fó/Brasilândia (SP): fóruns, redes, grupalidades
}

\author{
The collective practices in health \\ policies in Fó/Brasilândia (SP): \\ foruns, networks, groupalities
}

\section{El hacer colectivo en las políticas de salud de Fó/Brasilândia (SP): foros, redes, grupalidades}

\author{
Rosemary Haberland* \\ Cleusa Pavam** \\ Luiza Santa Cruz ${ }^{* * *}$ \\ Julia Hatakeyama Joia**** \\ Adriano de Oliveira**** \\ Patrícia Rodrigues Rocha**** \\ Maria Cecília Bonini Trenche ${ }^{* * * * * *}$
}

\section{Resumo}

Relata-se neste trabalho experiências de fazeres-coletivos de profissionais e serviços da rede de saúde do território Freguesia do Ó/Brasilândia, em São Paulo. Trata-se de um resgate histórico importante para o fortalecimento da integração ensino-serviço, que tem sido potencializada pelos projetos do Pró e Pet-Saúde desenvolvidos pela Pontifícia Universidade Católica de São Paulo em parceria com a Supervisão Técnica de Saúde da Freguesia do Ó/Brasilândia. O texto foi construído com base em pesquisa participativa que

*CER Fó/Brasilândia SMS/SP, São Paulo, SP, Brasil.

**Faculdade de Saúde Pública da USP, São Paulo, SP, Brasil.

***Secretaria Municipal de Saúde SMS/SP, São Paulo, SP, Brasil.

****Pró-Saúde PUC-SP / STS FÓ-Brasil, São Paulo, SP, Brasil.

*****Associação Saúde da Família - Secretaria Municipal de Saúde SMS/SP, São Paulo, SP, Brasil.

******Pontifícia Universidade Católica de São Paulo (PUC-SP), São Paulo, SP, Brasil.

Contribuições dos autores:

RH, CP, LSC, JHJ, AO, PRR, MCBT: coleta de dados, sistematização, escrita e revisão final.

E-mail para correspondência: Maria Cecília Bonini Trenche - cecilia@trenche.com.br

Recebido em: 23/01/2017

Aprovado em: 25/06/2017 
envolveu profissionais que atuaram e atuam nesse território. Narrativas orais construídas em oficinas foram ponto de partida para a escrita conjunta entre tutores e profissionais que manifestaram interesse por relatar as experiências de fazeres coletivos desse território. Um breve histórico de alguns espaços coletivos de articulação de redes no período "pós-Plano de Atendimento à Saúde" foi traçado, firmando o Fórum de Saúde Mental como precursor da afirmação de práticas compartilhadas de saúde, para além das paredes dos diferentes saberes e serviços. Outros espaços, como o Fórum da Infância e Adolescência, o Grupo de Trabalho Interdisciplinar e o Fórum de Reabilitação foram trazidos como importantes espaços que articulam o cuidado nas suas singularidades. A Política Nacional de Humanização foi apresentada como uma articuladora e potencializadora destes espaços. As narrativas dessas práticas e saberes evidenciam a potência deste fazer coletivo que fortalece a cogestão da saúde e amplia a integralidade do cuidado.

Palavras-chave: Saúde Pública; Gestão em saúde; Redes; Fóruns.

\section{Abstract}

This narrative brings the experience work of the collective way of producing health of professionals, networks and services from the territory Freguesia do Ó/Brasilândia, in Sao Paulo. This is an important historical recovery to strengthen the integration between university and health policies, which have been enhanced by Pro projects and Pet- health developed by Pontifícia Universidade Católica de São Paulo in partnership with Supervisão Técnica de Saúde da Freguesia do Ó/Brasilândia. The text was constructed based on participatory research involving professionals who acted and act in that territory. Initially from oral narratives, the text was produced together by tutors and professionals who have expressed interest in reporting the 2 experiences of collective practices on that territory. A brief history of some collective network spaces of the period "post-Plano de Atendimento à Saúde-PAS" was produced. The Mental Health Forum was described as a precursor of shared health practices, beyond the walls of different knowledges and services. Other spaces, such as the Child and Adolescent Forum, the Group of Interdisciplinary Work and the Rehabilitation Forum were brought as important spaces that articulate care in their singularities. The National Policy of Humanization was brought as an articulator and potentiating these spaces. The narratives of these practices and knowledges show the power of these collective practices, in order to strengthen the collective management of health and extend the comprehensive care.

Keywords: Public Health; Health Management; Networks; Forums.

\section{Resumen}

En este trabajo se relatan experiencias de haceres-colectivos de profesionales y servicios ofrecidos por la red de salud del territorio Freguesia do Ó/Brasilândia, en São Paulo. Se trata de un rescate histórico importante para el fortalecimiento de la integración enseñanza-servicio, que ha sido potenciada por los proyectos del Pro y Pet-Salud desarrollados por la Pontifícia Universidade Católica de São Paulo en asociación con la Supervisión Técnica de Salud de la Freguesia do Ó/Brasilândia. El texto fue construido em base a la investigación participativa realizada por profesionales que actuaron y actúan en este territorio. Las narrativas orales surgidas en los talleres realizados en este territorio fueron el punto de partida para la escritura conjunta entre los tutores y profesionales que manifestaron interés por relatar las experiencias de hacer colectivo.Fue delineado um resumen cronológico de algunos espacios colectivos de articulación de redes en el periodo del "Pos-Plan de Atención para la Salud", identificando el Foro de Salud Mental como el precursor de la afirmación de prácticas compartidas en salud, más allá de las paredes de los diferentes saberes y servicios. Otros espacios, como el Foro de Infancia y Adolescencia, el Grupo de Trabajo Interdisciplinar y el Foro de Rehabilitación también fueron reconocidos como ámbitos relevantes que promueven el cuidado em sus singularidades. La Política Nacional de Humanización des SUS fue presentada como articuladora y potencializadora de estos espacios. El relato de estas prácticas y saberes evidencia la pontencia de este hacer colectivo que fortalece la cogestión de la salud y amplía la integralidad del cuidado.

Palabras clave: Salud Pública; Gestión de la Salud; Redes; Foros. 


\section{Introdução}

\begin{abstract}
“(...) a territorialidade em seres humanos é mais bem compreendida como uma estratégia espacial para afetar, influenciar, ou controlar recursos e pessoas, pelo controle de uma área; e, como territorialidade pode ser ativada e desativada." (Sack, 1986)
\end{abstract}

A história das práticas da rede de atenção à saúde do território da Freguesia do Ó/Brasilândia (FÓ/Brasilândia), na cidade de São Paulo, tem sido fortemente marcada pela ação coletiva como forma de fazer saúde, pela afirmação de práticas que priorizam a integralidade e pelo compromisso com as necessidades de saúde da população e do território. Ao longo das últimas décadas, a formação de espaços coletivos que propiciassem grupalidades, articulações e diálogos entre os serviços e trabalhadores, sustentaram e vêm sustentando essa busca por maior integralidade nas ações e por formas mais democráticas, menos hierarquizadas e burocratizadas de se fazer saúde.

Esta comunicação apresenta alguns dispositivos de articulação de redes, de profissionais e de usuários da rede de serviços de saúde da região, ao longo da última década. Busca dar visibilidade, por um lado, à potência do fazer-coletivo, por outro, a sua forma viva e metamórfica de se produzir esses espaços. Acompanha a narrativa de constituição de diferentes dispositivos na forma de fóruns, encontros intersetoriais e de articulação do território, seus desdobramentos e transformações, tentando evidenciar a vivacidade com que conectam diferentes agentes e setores, além de fortalecer e multiplicar estratégias de cuidado no território.

Esses espaços coletivos são aqui tomados como dispositivos no sentido que atribui Foucault ${ }^{1}$ como um conjunto heterogêneo de elementos (discursos, medidas administrativas, enunciados científicos, filosóficos) que faz algo funcionar, disparando processos e que responde a uma urgência histórica. Sua função é estratégica e não deve ser vista como objeto isolado, mas nas conexões que cria ou constitui. Assim, tais espaços coletivos não se resumem a reuniões e aglutinação de pessoas, mas sim a múltiplos processos que respondem à necessidade de multiplicar o cuidado em saúde.

A noção de coletivo, por sua vez, também assume contornos específicos neste trabalho e se distancia de uma compreensão dicotômica que opõe o termo à ideia de indivíduo ${ }^{2}$. Interessa-nos tomar o coletivo como campo de relações entre planos distintos, mas não antagônicos, que são o plano das formas - ou o plano do instituído - e o plano das forças - ou o plano instituinte ${ }^{2}$. Tal entendimento pressupõe uma realidade produzida num jogo de forças permanentemente aberto à transformação. Cabe, todavia, a ressalva de que a constituição desses espaços não garante necessariamente um fazer-coletivo, mas o potencializam, ou seja, institui condições favoráveis ao acesso ao plano de criação e de produção de movimentos instituintes e de abertura para novas conexões a depender dos modos de operar nestes espaços ${ }^{3}$.

A presente narrativa sobre esse processo de fazer-coletivo funciona como ferramenta metodológica, pois constituiu-se tanto como dispositivo de comunicação, como de reflexão sobre práticas de saúde. E por isso, é particularmente importante para a saúde pesquisas em que as relações entre sujeitos e coletivo, memórias e ação política aparecem como questões de especial interesse. Constituindo-se como estratégia de pesquisa participativa, essa ferramenta metodológica envolve os próprios atores em várias retomadas de sua própria narrativa e propicia o contato deles com narrações de outros grupos de interesse ${ }^{4}$. Em se tratando de práticas sociais, os fazeres no campo da saúde carregam a potencialidade de se transformar, pela narrativa, em ação política. Por outro lado, a produção da narrativa atende ao imperativo ético-político de intervir no universo pesquisado, propiciando o fortalecimento de seus próprios agentes ${ }^{4}$.

Narrar os fazeres-coletivos, além de avivar a memória, produzir registros e material para contextualização de processos de formação em saúde, contribui para melhor compreensão da noção de território, propiciando uma discussão mais ampla, e, sobretudo, desde uma perspectiva política, sobre as necessidades, o planejamento e as ações de saúde desenvolvidas no território da FÓ/Brasilândia. Além disso, a narrativa opera a produção de analisadores ${ }^{5}$, ou seja, dá visibilidade a acontecimentos que evidenciam as linhas de força em jogo nas situações narradas.

Este manuscrito foi elaborado por profissionais que atuam no território FÓ/Brasilândia, docentes e tutores educacionais da Pontifícia Universidade Católica de São Paulo (PUC/SP) que integraram o projeto Pró-Saúde II (2008-2016), realizado em parceria com a Supervisão Técnica de Saúde 
(STS) da FÓ/Brasilândia, Coordenadoria Regional da Saúde Norte (CRSN), Secretaria Municipal de Saúde de São Paulo (SMS/SP).

A narrativa, em um primeiro momento, foca-se no processo de "reflorescimento" das práticas coletivas no início do século XXI. Optou-se por tratar nesta apresentação de experiências em espaços produzidos no período que ficou conhecido como "pós-Plano de Atendimento à Saúde (PAS)". Implementado pelo ex-prefeito Paulo Maluf em 1995, o PAS transferiu a gestão dos serviços de saúde para cooperativas de médicos, interrompendo um processo de alinhamento do município de São Paulo ao ideário do Sistema Único de Saúde (SUS) que vigorava na gestão anterior, de Luiza Erundina. Gerou a precarização dos serviços e o desmonte de práticas de territorialização, que incentivavam a incursão dos profissionais no território adscrito para conhecer sua realidade e suas demandas de saúde. Além de não respeitar princípios constitucionais do SUS, aprofundou contradições e conflitos entre a política do Município de São Paulo e a Política Estadual e Nacional de Saúde. Foi extinto em 2001 na gestão de Marta Suplicy que implementou uma política de reconstrução do SUS no Município de São Paulo.

O fim desse modelo de política de saúde propiciou o reflorescimento de experiências coletivas desejantes de inovações nas práticas de saúde e fortalecimento dos vieses público, universal e integral do SUS. Contudo, essa reconstrução do SUS "pós-PAS" ficou submetida a partir de 2006 às parcerias, por meio de convênios e contratos de gestão com as chamadas Organizações Sociais de Saúde (OSS), inicialmente apenas para seleção, contratação e capacitação de pessoal e, posteriormente, para a gerência dos serviços ${ }^{6}$.

$\mathrm{Na}$ segunda parte do texto, o relato foca-se nos processos impulsionados pela importante interferência da Política Nacional de Humanização (PNH), que buscou, desde 2008, fortalecer a articulação do território da FÓ/Brasilândia. Todavia, sempre que necessário, foram retomadas experiências anteriores a esse período que também se desdobraram em distintos espaços de articulação.

\section{Os espaços coletivos e suas}

\section{transformações}

\section{O Fórum de Saúde Mental}

Uma das primeiras experiências de espaços que articulavam diferentes profissionais e serviços da região no período "pós-PAS" foi o Fórum de Saúde Mental, em 2001. Nesse período, o território já contava com equipes de Saúde da Família, gerenciadas pela Fundação Zerbini e o governo do Estado havia ampliado o então chamado Programa Saúde da Família (PSF) na região, sendo que algumas Unidades Básicas de Saúde (UBS) inicialmente foram gerenciadas pela Secretaria Estadual da Saúde (SES) e posteriormente, com a municipalização da saúde, pela OSS Associação Saúde da Família (ASF) ${ }^{7,8}$.

Cabe lembrar que o território da Freguesia do Ó e Brasilândia concentrou, na década de 80 , um grande número de hospitais psiquiátricos ${ }^{9} \mathrm{e}$ vivenciou na gestão municipal de Luiza Erundina (19891993) a implantação de equipes de saúde mental nas UBSs, com investimentos em alternativas à internação psiquiátricas (Hospital Dia, Centros de convivência, entre outros) o que reaproximou a Saúde Mental da Atenção Básica que passou, então, a contar com equipes multiprofissionais com atuação interdisciplinar.

Em 1997, a FÓ/Brasilândia participou do Projeto Qualidade Integral QUALIS II-PSF, que tendo em vista as condições desfavoráveis do PAS, implementou a Estratégia de Saúde da Família e o Programa dos Agentes Comunitários de Saúde por meio de uma parceria entre a Fundação Zerbini e a Secretaria do Estado, levando os profissionais a retomarem o processo de territorialização e mobilização da comunidade.

Nesse contexto, a Saúde Mental tinha por objetivo que suas ações abrangessem todo o território, ainda que as UBSs sob o gerenciamento da ASF não contassem com equipe de Saúde Mental e as administradas pela Prefeitura Municipal de São Paulo (PMSP) tivessem em seus quadros de recursos humanos poucos profissionais de Saúde Mental. Como agravante, havia o fato de o Ambulatório de Saúde Mental da Brasilândia receber demandas não só das regiões vizinhas, mas também de localidades distantes, inclusive de outros municípios. Assim, era necessário estreitar o diálogo com as redes dessas localidades, bem como fortalecer a territorialização e regionalização do atendimento. 
A partir dessa avaliação e preocupação, o Fórum de Saúde Mental foi incentivado por Lidia Siqueira Tobias, responsável pelo Distrito de Saúde na época, para se constituir em um dispositivo de integração e articulação das ações em Saúde Mental no território. Nas primeiras reuniões, foram convidados todos os profissionais de Saúde Mental das Unidades de Saúde da região, como psicólogos, terapeutas ocupacionais, assistentes sociais, psiquiatras, além da equipe do Ambulatório de Saúde Mental. O Fórum foi, então, realizado quinzenalmente, sediado inicialmente no Ambulatório de Saúde Mental e posteriormente, de forma itinerante - propositadamente para que os profissionais pudessem estreitar as relações e conhecer melhor as instituições do território - pelos serviços de Saúde, Unidades Básicas, Pronto Socorro e Ambulatórios. O primeiro documento do Fórum foi redigido como forma de diálogo com serviços de saúde de outros territórios, onde se informava a lógica territorial de atendimento, buscando organizar os limites entre a vizinhança da Brasilândia.

Era necessário estancar a chegada de grande quantidade de pacientes para o Ambulatório da Brasilândia que buscavam os mais diferentes tipos de atendimento, podendo e devendo tê-los nas Unidades de Saúde mais próximas de sua residência. As novas diretrizes da Saúde Mental privilegiavam o atendimento a pessoa em sofrimento psíquico no território, onde deveria estar sendo auxiliada na relação com as pessoas de sua convivência e não mais isolada para "receber tratamento". Aos poucos, documentos norteadores começaram a ser produzidos pelo Ministério de Saúde ${ }^{10,11}$.

Esse momento impulsionou profissionais que já atuavam na região, assim como aqueles que haviam recentemente chegado por meio de concurso, com muita abertura para pensar e inventar novas práticas em saúde. Nesse momento "pós-PAS", a produção de novos fazeres no campo da saúde alimentava aqueles que vinham de um período em que predominou o esvaziamento e desinvestimento dessas ações, bem como o sentimento de "enviuvamento" do modo de fazer saúde antes do PAS.

A experiência das equipes volantes de saúde mental, instituídas alguns anos antes pelo PSF, trazia uma forte marca aos encontros, colocando em discussão a necessidade de a função matriciamento ser assumida pelos profissionais da Saúde Mental, diretriz que ganhava força no campo da Saúde ${ }^{12}$, assim como a "saída" destes das suas unidades para o território. Apesar de a grande maioria dos profissionais trazer um comprometimento com os princípios que regiam essas práticas, alguns resistiram às novas proposições, pedindo transferência ou questionando a necessidade de realizarem matriciamento devido à formação pautada em modelos tradicionais (foco na doença, na lógica queixa conduta e na especialidade $)^{13}$.

O Fórum, nesse contexto, surge como um polo aglutinador que fomenta discussões sobre os desafios enfrentados, onde os profissionais podiam fortalecer suas práticas e fazer alianças. As discussões, muitas vezes, giravam em torno de casos, de forma a promover conjuntamente questões sobre o funcionamento dos fluxos e da rede, e novas soluções eram acionadas na coletividade. Seu foco era discutir as diversas questões do SUS, bem como de seus trabalhadores e a reflexão em relação às políticas públicas, sendo um espaço aberto a qualquer trabalhador da saúde e de outros setores.

Em 2008, a constituição dos Núcleos de Apoio à Estratégia Saúde da Família (NASF) no território propiciou a ampliação do quadro de profissionais (contratados pela organização social ASF) e, portanto, possibilitou a inclusão de outras categorias profissionais além daquelas consideradas Saúde Mental. Assim, o nome do Fórum foi alterado para "Fórum dos Trabalhadores da Saúde", dando continuidade ao espírito guerreiro da região, contribuindo para outras conquistas do território como as Residências Terapêuticas e o Centro de Atenção Psicossocial Infantil (CAPSi) em 2009 e o Centro de Atenção Psicossocial Álcool e outras Drogas (CAPSad) em 2011.

Como tem sido habitual na mudança de gestão pública, em 2009, o território teve seu corpo de gerentes modificado, pois a nova gestão da SMS decretou que os gerentes deveriam ser contratados pelas Organizações Sociais de Saúde, parceiras da Secretaria Municipal de Saúde na gestão da saúde, ao invés de terem vínculo público, mudando assim todo o apoio ao curso de formação na PNH e continuando a longa trajetória de relações entre gestão pública e gestão das Organizações Sociais de Saúde Associação da Saúde da Família (ASF) e Associação Paulista para o Desenvolvimento da Medicina (SPDM).

Com tantas mudanças, ampliações e reorganizações territoriais, o espaço do Fórum dos Trabalhadores de Saúde encontrava-se muito esvaziado e passou a fomentar a criação de outros espaços de 
discussão no território, frente aos desafios permanentes que se colocavam. A pouca integração na Secretaria Municipal de Saúde entre Atenção Básica e outras áreas temáticas como, por exemplo, Saúde Mental, implicava em orientações antagônicas para o mesmo serviço. Da mesma forma, os contratos que foram se estabelecendo com diferentes parceiros nas regiões vizinhas estabeleciam práticas sustentadas pelas mais diversas lógicas em saúde e influenciavam também a caótica multiplicidade de direções na Saúde.

A partir da necessidade de articulação entre Núcleo de Apoio a Saúde Família (NASF) e Centro de Atenção Psicossocial (CAPS) para ampliar as possibilidades de cuidados em Saúde Mental no território e fortalecer a construção de apoio matricial para as equipes de Atenção Básica, articularam-se espaços de encontro denominados microrredes. Os Serviços de Saúde da STS da Freguesia do Ó/Brasilândia foram organizados em três grupos denominados microrredes, a fim de facilitar o enlace desses serviços e considerar singularidades geopolíticas e territoriais desse território. A microrrede Beira Rio, composta por serviços que estão geograficamente mais próximos da região do Rio Tietê; a microrrede Alta da Serra, composta por serviços que estão na região geográfica mais alta da Brasilândia, próximos à Serra da Cantareira; e a microrrede Pé de Serra, composta pelos serviços que ficam mais próximos do pé da Serra da Cantareira. Os serviços estratégicos como CAPS (II, AD e infantil), Centros de Referência em DTS/AIDS (CRDTS/AIDS) e Centro de Referência Saúde do Trabalhador (CRST) têm representantes em todas as microrredes. Esses grupos inicialmente criados para profissionais das equipes NASF e CAPS, hoje contemplam também gestores das Unidades Básicas de Saúde, profissionais das Equipes da Saúde da Família e têm seu objetivo ampliado, já que se considerou necessário discutir temas importantes para a sustentação da Rede de Atenção Psicossocial com estes atores.

A organização do território em microrredes foi estratégia organizadora para a proposta de intervenção da PNH sobre acolhimento e classificação de risco, além de ter intersecção relevante com a PUC-SP por meio dos projetos Pró e PET-Saúde. Ou seja, é neste espaço que a rede de saúde encontra hoje terreno fértil para discussões e qualificações da rede sobre temas e conceitos fundamentais para sustentação da clínica ampliada ${ }^{14}$ e dos cuidados em Saúde Mental da população. A exemplo disso as microrredes têm pensado, com apoio do PET Saúde Mental, processos de cuidados de adolescentes em uso abusivo de álcool e drogas; medicalização e uso racional de medicamentos, violência no território e saúde do trabalhador ${ }^{15}$.

Neste contexto, a sustentação das microrredes como espaço coletivo de composição da Rede de Atenção Psicossocial (RAPS) tem revertido em uma série de propostas de intervenções coletivas com a população, além da sustentação dos processos de apoio matricial e da cultura desse território de cuidado em rede e cogestão ${ }^{16}$.

\section{A integração na Atenção Básica: reuniões de gerentes de UBS}

No processo "pós-PAS", marcado pelas constantes reformulações organizacionais e da gestão da saúde no território, as UBSs, por sua vez, sofriam investimento permanente de uma política ainda medicocêntrica atrapalhando-se cada vez mais entre a Política Municipal e a Nacional. Um importante coletivo formado para propulsionar a integração entre a rede da Atenção Básica foi a reunião de gerentes das UBSs. Em 2002, todos os gerentes do município foram chamados para uma capacitação conjunta, o Gerência de Unidades Básicas de Saúde (GERUS), pela Secretaria de Saúde Municipal. O GERUS foi um curso de especialização em gerência de UBS, desenvolvido com a cooperação técnica da Organização Pan-Americana de Saúde-PAS e do Ministério da Saúde-MS, por meio de uma parceria com a Faculdade de Saúde Pública da Universidade de São Paulo (FSP/USP). Diante do contexto da implantação dos Distritos de Saúde no município, buscava possibilitar aos gerentes um novo papel de articulação, mobilização, negociação local. A formação durou um ano, mas logo no retorno do PAS, a região da FÓ/ Brasilândia decidiu organizar um grupo com os seus gestores, que se reuniam semanalmente, a fim de dinamizarem e afinarem os trabalhos realizados na Atenção Básica. Em 2005, foi instituída nova regionalização dos serviços de saúde do município, com a criação de cinco Coordenadorias de Saúde e vinte e quatro STS, sendo a da região Santana localizada em Santana, incluindo a STS Freguesia do Ó/Brasilândia.

Assim, a partir das necessidades que identificavam em cada território de UBS, as questões eram discutidas na reunião, onde todos eram convocados 
a pensar em soluções. Essas reuniões passaram a ter efeitos também no cotidiano das Unidades, cujas gerências começaram a trabalhar de forma mais interligada, estabelecendo canais de diálogo e apoio contínuos e mútuos. Esse grupo mantinha trocas importantes com o próprio Fórum de Saúde Mental, levando demandas de discussão e apropriando-se daquilo que era discutido. As UBSs sediavam o Fórum, itinerante pelas Unidades de Saúde e responsabilizavam-se em coordenar suas discussões em sua vez de recepcioná-lo.

Conforme já relatado, a gestão municipal de 2009 exigiu que os gerentes não tivessem vínculo público. A exigência de que os gerentes tivessem ou não vínculo público foi alternada de acordo com a concepção de gestão por parte do partido político que ganhasse as eleições, e isto aconteceu pelo menos por duas vezes em diferentes eleições para a Prefeitura de São Paulo. Cogestores foram contratados pelas OSSs por meio de um rápido processo seletivo, desestabilizando os serviços do território e o Fórum dos Trabalhadores da Saúde. O novo grupo de gerentes, não mais formado por aquele modo de agir coletivo constituído historicamente, passou a receber outras influências nas UBSs e, isto somou-se a vários outros fatores como: alta rotatividade dos profissionais nas UBSs, problemas de mudanças importantes na composição das Unidades, construção de outros espaços de discussão como o Fórum de Redes na FÓ/Brasilândia, a partir do Grupo de Trabalho Humanizado (GTH), bem como a chegada de outros serviços CAPSi, CAPSad, Centro Especializado de Reabilitação (CER), Núcleo Integrado de Reabilitação (NIR), o que foi promovendo a desmobilização do Fórum dos Trabalhadores, tornando-o sem sentido, o que culminou em seu término, por volta de 2010/2011.

Em 2008, a STS FÓ/Brasilândia participou do curso de Formação de Apoiadores da PNH, apostando na formação do corpo de gerentes das UBSs, a fim de intensificar as discussões a respeito dos modos de produção de saúde no território e a construção de dispositivos de intervenção que pudessem favorecer a melhoria e qualificação da atenção aos sofrimentos e necessidades das pessoas residentes no território. Esse curso foi um investimento do Ministério da Saúde e Secretaria Estadual de Saúde, e se propunha a envolver, inicialmente, somente profissionais de alguns Hospitais do Estado de SP. Mas, graças ao empenho e apoio de vários profissionais, ofertou seis vagas à Atenção Básica do município de São Paulo. A composição, então, da Unidade de Produção São Paulo-Capital, denominação dada ao grupo, foi: Geralda Ap. Vieira de Carvalho e Ivonete de Paula pelo Hospital Geral de Vila Nova Cachoeirinha "Dr. Álvaro Simões de Souza"; Marisa Cristina Domingues e Sheila Cristina Ribeiro dos Anjos pelo Hospital Geral "Doutor José Pangella" Vila Penteado; Vera Lúcia Patrezze, Viviane de Araújo Arantes e Maria Cristina Coelho Nepomuceno Carvallho pelo Conjunto Hospitalar do Mandaqui; Rosângela Braga Gomes e Izilda de Barros Gatto pela STS Casa Verde/Cachoeirinha/Limão; Josefina Sanches pela STS Pirituba/ Perus; Rosemary Haberland, Danielli Marques e Teresa Cristina Fenerich de Moraes pela STS FÓ/ Brasilândia; e teve como Formadora Maria Luiza Santa Cruz e Apoiadora Pegagógica Maria Cristina Vicentin (PUC/SP) e Cleusa Pavan como apoiadora da PNH para São Paulo.

O curso previa que seus formandos realizassem um plano de intervenção em seus serviços e que utilizassem as ferramentas da PNH para difusão das diretrizes do SUS. A formanda que mais estendeu seu Plano de Intervenção no Serviço, trabalho obrigatório do curso, foi Rosemary Haberland, que conforme solicitação dos primeiros gestores construiu um GTH com toda a STS da FÓ/Brasilândia. O GTH durou de 2008 a 2015, tendo sido contemplado com o apoio institucional de Cleusa Pavan de 2010 a 2015. Concomitantemente, a $\mathrm{PUC/SP}$ permanecia com os estágios no território e avançava em 2012 com a proposta de PET Saúde Mental em quatro UBSs da mesma Supervisão Técnica de Saúde.

\section{Intersetorialidade nos temas da infância e juventude: O Fórum da Infância e Adolescência e o Grupo de Trabalho Interdisciplinar (GTI)}

Foi a partir do encontro entre os profissionais de Saúde Mental (SM), incentivado por Dra Lidia Siqueira Tobias, e por meio da discussão de um caso cuja história é relatada no livro Saúde e Loucura ${ }^{17}$, de um garoto de sete anos da UBS Galvão, acompanhado pela equipe de Saúde Mental Qualis, que em fevereiro de 2001 iniciaria seu $1^{\circ}$ ano em Escola Municipal de Ensino Fundamental, demandando amplo trabalho intersetorial de reflexão para sua inclusão no ensino regular, que conhecemos Wagner Rañna e sua equipe na Educação.

Por meio desse caso e pelo contato da recém-chegada fonoaudióloga na Saúde, vinda da 
Educação, iniciamos uma conversa com a equipe da Educação sobre a inclusão de crianças que apresentavam problemas em sala de aula. Conhecemos, por meio de uma profissional de fonoaudiologia da UBS Ladeira Rosa, Wagner Rañna e Marly Gandolfo que já desenvolviam um trabalho de inclusão de crianças com transtorno global de desenvolvimento em salas de aula comuns. Dessa conversa iniciamos encontros mais sistemáticos, cujo objetivo era identificar demandas relativas ao desenvolvimento de crianças e adolescentes que necessitavam de outros investimentos em espaços de discussão mais específicos e intersetoriais. Assim, surgiu o Fórum da Infância e da Adolescência, espaço de intersecção Saúde e Educação, em 2001.

Esse espaço foi ganhando densidade e rapidamente passamos, então, a ter um Fórum oficialmente constituído com a denominação já mencionada anteriormente e que acontecia mensalmente no antigo Núcleo de Ações Educativas - Norte (NAE 3). O Fórum chegou a discutir e agenciar redes em torno de mais de 400 crianças, quando, em 2005, com a troca de gestão municipal e as mudanças na Educação, esse trabalho foi radicalmente extinto. Apesar disso, essa iniciativa deu origem ao Fórum Municipal da Criança e do Adolescente, em 2004, que passou a discutir intersetorialmente a necessidade das crianças e dos adolescentes nos diferentes serviços públicos que deveriam ser responsáveis pelo crescimento e desenvolvimento dessa população.

$\mathrm{Na}$ época, o Ambulatório Maria Cecília Donnangelo participava ativamente dos fóruns e alguns serviços próximos a ele, como a Escola Estadual Chiquinha Rodrigues e o Circo Escola Vila Penteado, posteriormente a UBS Vila Penteado, iniciaram fóruns locais para discussão de alguns casos que frequentavam essas instituições. A ideia praticada pela psiquiatra Silvia Regina Fenerich e a Terapeuta Ocupacioal, Amabel Simões, à luz já das discussões de caso no Fórum de Saúde Mental, era envolver os diferentes profissionais que se relacionavam com uma mesma criança/adolescente e traçar projetos de saúde dos envolvidos. Assim, a cada caso que chegava para atendimento, localizavam-se quais serviços estavam envolvidos para organizar a compreensão e formas mais integradas de atenção à saúde. Reuniam-se então, escolas, Conselho Tutelar, UBSs, Circo Escola e quem mais pudesse se agregar ao projeto.
Na FÓ/Brasilândia, o Fórum de Saúde da Criança e do Adolescente seguiu sem a participação da Educação, a partir do embrião do entorno do Circo Escola com a já UBS Maria Cecilia Donnângelo. Isso porque a mudança de gestão pública produziu em 2005 o desmonte da equipe da Educação que, junto com Wagner Ranna discutia e fazia a inclusão de crianças, assim como a proibição da participação de professores, coordenadores pedagógicos e outros profissionais no Fórum com a Saúde, inviabilizando que participassem deste espaço.

Em discussão no Fórum dos Direitos da Criança e do Adolescente, de iniciativa da sociedade civil, com a presença da equipe técnica da Secretaria Municipal de Educação de São Paulo (SME/ $\mathrm{SP}$ ), esta explicou que esse trabalho não mais seria possível, pois tinha o objetivo de retomar a função da escola que era: ensinar a ler e escrever. Com esta postura, as 400 crianças tiveram negada sua entrada nas salas comuns e as salas "especiais" voltaram a existir. Muitas crianças voltaram para seu isolamento em casa, podadas de uma convivência estimulante que é o espaço da escola.

Apesar dessa negativa de intersetorialidade da Educação nesse momento, a Saúde continuou com o objetivo de discutir casos de crianças/adolescentes com dificuldade de aprendizagem e suas famílias com os profissionais envolvidos (saúde, educação, conselho tutelar, etc.) para construir projetos terapêuticos com a rede; procurando ampliar a integração da rede e discutir questões do trabalho relacionado à infância e adolescência.

Em 2007, identificava-se novamente a necessidade de fomentar e articular as políticas voltadas para a infância e adolescência. Nesse ano, o IV e último Encontro de Saúde Mental, organizado pelo então Fórum de Saúde Mental, teve como tema: "Infância e adolescência: qual o diálogo possível entre as instituições?", reunindo diferentes setores como Saúde, Educação, nos níveis estadual e municipal, Ministério Público, Conselho Tutelar, Vara da Infância e Adolescência, Organizações Não Governamentais (ONGs), Instituto Sou da Paz/ Espaço Criança Esperança, PUC/SP, entre outras.

A partir da identificação de impasses nos encaminhamentos de casos, evidenciou-se a necessidade de fomentar a articulação intersetorial no território, como forma de possibilitar aos usuários $\mathrm{o}$ adequado acesso às políticas públicas. Com a necessidade de se manter encontros intersetoriais mais permanentes é que o Grupo de Trabalho In- 
terdisciplinar (GTI) passou a ser denominado como tal. Informação para os serviços era algo muito importante para se priorizar e então o GTI passou para a realização de um mapa em uma plataforma da internet, que incorporasse os serviços voltados à infância e adolescência do território e que pudesse ser facilmente consultado. O mapa mostra endereços e dados sobre atendimento nas áreas da Saúde (Postos de Atendimento), Educação (Escolas Municipais e Estaduais), Assistência Social (Unidades do Centro de Referencia em Assistência Social), Esporte (Ruas de lazer e Clubes da Comunidade), Habitação (Supervisão - Subprefeitura), Cultura (Casas de Cultura e Bibliotecas), Fóruns (Freguesia e Lapa) e Conselho Tutelar. Além destas, outras entidades que desenvolvem projetos no território também compuseram o mapa, como ONGs e o Espaço Criança Esperança.

O GTI segue funcionando, reunindo representantes do poder público e sociedade civil, mas com pouca troca com os demais coletivos do território. O Fórum da Infância e da Adolescência segue com encontros mensais, com a participação variável da Educação, com a presença constante de trabalhadores e que no início do segundo semestre de 2016, contava com a participação do Núcleo de Apoio e Acompanhamento para Aprendizagem (NAAPA), braço importante da Educação. Atualmente o GTI é composto por: Vara da Infância e Juventude do Foro Regional IV $\square$ Lapa, Coordenadoria do Centro de Integração da Cidadania (CIC Norte), Supervisão Regional de Saúde Freguesia/Brasilândia, Supervisão Regional de Assistência Social $\square$ Centro de Referência de Assistência Social-CRAS Freguesia/Brasilândia, Diretoria Regional de Educação Freguesia/Brasilândia, Subprefeitura Freguesia/ Brasilândia, Instituto Sou da Paz/Espaço Criança Esperança São Paulo, Supervisão de Habitação, Supervisão de Cultura e Supervisão de Esportes.

\section{Fórum Reabilitação}

O tema da saúde das pessoas com deficiência necessitou muitos esforços para que saísse de seu histórico patamar da invisibilidade e da segmentação do cuidado. Até final dos anos 2000 e início da década de 2010, os serviços com profissionais de reabilitação (fisioterapeutas, fonoaudiólogos, terapeutas ocupacionais, psicólogos) trabalhavam de forma isolada, isto é, com base em concepções e intervenções fragmentárias, expressas em aten- dimentos especializados das profissões que atuam nesse campo.

A chegada do NASF, em 2008, constatou a inexistência de investimento na área de reabilitação na região, o que fazia com que as UBSs tivessem pouco ou nenhum conhecimento do trabalho com a população com deficiência, que era realizado pelo único serviço de reabilitação até então, o NIR Maria Cecília Donnângelo. Iniciou-se uma possibilidade de ampliar o olhar e construir um coletivo em torno da política de reabilitação, pois profissionais desta área trouxeram experiências e conhecimentos para agregar aos tímidos e pequenos, não tão menos importantes, serviços como os NIR. No trabalho cotidiano as equipes NASF percebiam que, muitas vezes, as necessidades de saúde da pessoa com deficiência eram pensadas apenas na perspectiva da doença ou pelos comprometimentos funcionais consequentes.

Trabalhar no campo da Reabilitação na Atenção Básica implicava, portanto, ampliar essa compreensão, analisar os processos sociais, que são extremamente complexos, como condicionantes e determinantes agravos à saúde e incapacitações. Implicava ir além do aspecto orgânico individual e incluir análise de trocas sociais e da autonomia, compreender a relação da pessoa com deficiência com o contexto histórico-social e com as dimensões subjetivas. Surge, então, a necessidade de incluir os casos de reabilitação nas discussões entre equipes NASF/PSF, cujo enfoque era predominantemente na Saúde Mental, a fim de produzir práticas de cuidado mais ampliadas e compartilhadas.

Assim, em 2009, uma comissão entre os sete NASF da região passou a discutir como expandir a política de reabilitação no território e em junho de 2010, formou-se o embrião do Fórum de Reabilitação, composto por profissionais do NASF, do NIR e do Programa de Acompanhante à Pessoa com Deficiência (APD). Essa comissão embrionária ampliou posteriormente a participação para outros serviços do território, transformando-se em um Fórum aberto de discussão da Política de Reabilitação para o território FÓ/Brasilândia. Como a STS Cachoeirinha/Casa Verde/Limão não possuía NIR e os usuários eram referenciados para os NIRs da STS FÓ/Brasilândia, o Fórum incorporou profissionais das duas supervisões técnicas de saúde. Incorporava-se, então, um debate entre profissionais de diferentes territórios e a discussão conjunta sobre estratégias de cuidado. Esse espaço 
propiciou, ao tema da reabilitação e os profissionais da área, uma maior visibilidade e espaço dentro da STS da FÓ/Brasilândia e também fomentou a maior integração entre os serviços e equipes, potencializando as discussões dos casos envolvendo a reabilitação com a ampliação do acesso aos usuários.

A chegada do Pró Saúde pela PUC/SP no território e por sua proposta de também acompanhar os diferentes fóruns existentes fez os estágios se aproximarem do Fórum de Reabilitação, o que posteriormente incentivou a PUC/SP a desenvolver também o PET-Redes de Atenção à Pessoa com Deficiência, uma vez que já desenvolvia o PET-Saúde Mental, o que propiciou a participação mais sistemática de professores e estudantes da PUC/SP nos Fóruns de Reabilitação.

Com a parceria entre a STS FÓ/Brasilândia e a PUC/SP através do Pró-PET Saúde, houve a possibilidade de contratação da assessoria de Ana Rita de Paula e Érica Pisaneshi, que contribuíram com discussões conceituais para uma maior compreensão do modelo de atenção à saúde da pessoa com deficiência do SUS. Outro apoio importante para o território, que muito contribuiu para a constituição do Fórum e qualificação para as discussões dos processos de trabalho, foi o da $\mathrm{PNH}$, que será apresentado a seguir.

Esses investimentos, o desejo de produzir mudanças dos profissionais que estavam bastante motivados, as discussões do Fórum, que teve também o apoio das Professoras Maria Cecília Bonini Trenche e Laura Wëy Martz do curso de Fonoaudiologia da PUC/SP, geraram muitos movimentos no território, como discussões para: reverter a situação de invisibilidade em que se encontravam as pessoas com deficiência no território; definir os papéis da Atenção Básica e na Atenção Especializada no cuidado dessa população e a articulação dessas instâncias; pensar a inclusão não somente nos serviços de saúde, mas na família, na comunidade, na vida, constituir fluxos e redes solidárias e formar a rede quente que tanto desejamos em consonância com os princípios de SUS da integralidade e equidade.

Grandes ganhos foram e estão sendo sentidos diariamente no cotidiano das práticas de saúde desde o acolhimento, a forma de olhar, reconhecimento de necessidade de saúde gerais e específicas (relacionadas à deficiência) ${ }^{18}$, rompimento de diversas barreiras, principalmente as atitudinais, que proporcionam maior acesso para os usuários e aproximação dos profissionais e serviços.

\section{A política nacional de humanização e seus efeitos de potencialização dos coletivos no território}

Importante marco do fortalecimento das ações coletivas e da formação e qualificação de redes na região aconteceu, também, por meio da Política Nacional de Humanização. A PNH, desde 2008, fomenta ações no sentido de capacitação e qualificação do SUS, do respeito aos seus princípios e na direção da democratização da gestão da saúde. A humanização é compreendida como uma "aposta radical em modos cooperativos dos sujeitos se relacionarem, trabalharem, fazerem gestão de serviços, gestão da clínica, organizarem processos de trabalho, acolherem usuários, transformarem suas práticas e se cuidarem"19,20.

Em 2008, constituiu-se, na região da FÓ/Brasilândia, o Grupo de Trabalho de Humanização, dispositivo da PNH com o intuito de propiciar a reflexão, discussão e transformação da atenção e gestão em saúde nos territórios, por meio da inclusão de trabalhadores, gestores e usuários em rodas de conversa e construção de estratégias para enfrentar os desafios do trabalho em saúde.

\section{Grupo de Trabalho de Humanização (GTH)}

Apoiado a partir de 2010 por dois consultores, Cleusa Pavan e Bruno Mariane, da PNH-Ministério da Saúde, o GTH da FÓ/Brasilândia escolheu duas diretrizes como ferramenta de trabalho para os anos seguintes: Cogestão e Redes.

Como disparador das ações, em outubro de 2010, o GTH realizou o I Encontro de Humanização da FÓ/Brasilândia, na sede da "Escola de Samba Sociedade Rosas de Ouro". Participaram aproximadamente 250 trabalhadores, gestores e usuários, que puderam dar a conhecer suas concepções de Cogestão e Redes, escutar as concepções da PNH, trocar ideias a respeito e manifestar interesse em experimentar formas de fazer gestão compartilhada em suas Unidades/Serviços e formas de trabalhar em rede. Foram construídos, a partir desse encontro, Planos de Trabalho para a implementação da Gestão Compartilhada nas Unidades e Articulação dos Serviços, visando a democrati- 
zação das decisões e a integralidade do cuidado à saúde no território.

Cada serviço, a seu modo e em seu tempo, respeitando-se as singularidades em jogo, incrementou e/ou começou a experimentar, por exemplo, reuniões gerais com caráter menos prescritivo (mais colaborativo e deliberativo); reuniões de apresentação dos diferentes setores de cada serviço para aquecimento da rede interna; reuniões de mini-equipes; construção de GTHs locais; construção de Conselhos Gestores onde não havia; organização de cozinha comunitária dos trabalhadores; realização de assembleias comunitárias; reuniões trimestrais (por equipes de saúde da família) com a comunidade para planejamento e avaliação; reuniões com outros equipamentos de outras políticas (escolas, abrigos, Centros Culturais da Juventude) ressignificação e/ou instituição da Comissão Técnico-Administrativa como coadjuvante da gestão das unidades; reuniões multiprofissionais para discussão de fluxos, processos de trabalho, etc.; incremento das atividades de terapia comunitária e reuniões de integração entre STS- FÓ/ Brasilândia supervisão e ASF, organização parceira do território) etc.

Como desdobramento do I Encontro, foram organizados distintos espaços de articulação como, por exemplo, o Fórum de Redes, que promoveu o encontro de todos os serviços da STS, incluindo os Hospitais que são referência para o território, visando o aquecimento da rede, a ampliação da corresponsabilidade, a melhoria da qualidade do cuidado e a garantia da integralidade. Ou então o Grupo de Trabalho de Saúde Mental, constituído para a construção de um projeto ético-político de saúde mental para o território. Também, instituiu-se o Grupo Gestor do território, Grupo de Cogestão, espaço criado como desdobramento do plano de trabalho de cogestão da STS, que objetivava ampliar o espaço de diálogo e cogestão da Política de Saúde implementada em parceria STS e ASF, buscando uma gestão integrada para a produção de saúde no território.

Alguns casos clínicos que passaram a ser levantados no Fórum de Redes, os denominados Casos Sentinela, necessitavam uma discussão ainda mais ampliada, sendo levados para discussão em reuniões mensais junto a representantes dos serviços de Saúde Mental, atenção básica, STS, PUC/ SP, ASF, para acompanhamento dos atendimentos, discussão de Projeto Terapêutico Singular- PTS e responsabilização pelo cuidado. Essa atividade ocorreu de maio de 2011 a abril de 2013, integrando trabalhadores e gestores dos vinte e nove serviços da região (Grupo de Trabalho de Redes) junto com três Hospitais Estaduais e um Pronto Socorro administrados por uma Organização Social.

Tais casos eram aqueles que, de alguma forma, tornavam-se analisadores da rede de serviços, sendo situações de usuários cujo fluxo de atendimento havia se interrompido, gerando descontinuidade no tratamento ou ocupação desnecessária de leitos hospitalares caso houvesse acolhimento em outros serviços. Resumidamente, situações em que a integralidade, resolutividade e qualidade da atenção estavam muito aquém do desejado e gerando sofrimento para trabalhadores, gestores e usuários.

No ano seguinte, o GTH trabalhou no sentido de acompanhar os planos de trabalho e as experimentações de humanização em curso. O tema da atenção em rede e a (des)articulação do sistema de saúde concentrava grande parte dos desafios do território, demandando um investimento de proporções mais significativas nos próximos tempos. Assim, o GTH da FÓ-Brasilândia propôs um II Encontro de Humanização, realizado em 2012, com o tema "Redes de produção de saúde" intitulado: "Da rede que temos à rede que queremos". Este Encontro expressou, por um lado, um desejo de intensificação do aquecimento das relações entre trabalhadores, gestores e usuários dos diferentes serviços da região, por outro, a necessidade de colocar em relação e/ou dar a conhecer os diferentes espaços/redes já organizados no território e, por fim, uma aposta no aprofundamento da análise da situação da saúde, em rede, no território e na instrumentalização conceitual para o enfrentamento das dificuldades de fazer Rede Quente, de garantir saúde integral a usuários e trabalhadores da FÓ-Brasilândia ${ }^{21}$.

Assim, a PNH no território da FÓ-Brasilândia foi se afirmando como experimentação de sujeitos concretos que de forma singular utilizam diretrizes, dispositivos e método como ferramentas para repensar a si mesmos, os processos de trabalho e o SUS 22.23 .

\section{Grupo de Trabalho de Redes (GT Redes)}

Foi formado um Grupo de Trabalho de Redes (GT Redes) com participação de todos os serviços: gerentes, conselheiros gestores, gestores da STS e 
da ASF, que existiu durante dois anos e teve como primeira atividade a apresentação de todos os serviços em roda de conversa envolvendo também hospitais referência da região. Nestes encontros foram emergindo analisadores que davam visibilidade a situações de usuários sem equipe responsável, sem destino, com tratamentos interrompidos por falta de articulação entre hospitais com as demais unidades, entre outros. Com isso, abriu-se uma nova fase de trabalho: o trabalho de análise de situação da atenção em Saúde Mental. A partir da discussão de cinco casos de usuários de Saúde Mental - oportunidade que se demonstrou de uma riqueza sem precedentes - a palavra circulou e com ela afetos, hipóteses sobre os modelos de atenção em Saúde Mental operantes no território, constatações sobre as insuficiências de equipamentos e trabalhadores, consensos importantes em termos de mapeamento do campo problemático. Um ponto crítico reiterado foi a falta de preparo das equipes de UBS e das unidades de Assistência Médica Ambulatorial (AMA) para o acolhimento dos usuários de Saúde Mental e a falta de retaguarda por parte dos CAPS.

$\mathrm{O}$ tema do apoio matricial dos CAPS às unidades de saúde de seus territórios entrou em cena. Duas lógicas de matriciamento estavam em operação: i) CAPS fazendo discussões semanais de casos nas unidades e disponibilizando-se para manejos conjuntos de situações de crise, com responsabilização pelo seguimento e ii) CAPS "com portas fechadas", que nunca se deslocavam para as unidades, mantendo reuniões esporádicas em suas próprias sedes para discussão de casos, indisponíveis para manejos conjuntos.

Outro ponto crítico apontado foi a falta de articulação dos CAPS e UBSs com os hospitais e Prontos Socorros quando das internações: CAPS e UBSs desresponsabilizando-se pelos usuários internados, ausência de Projeto Terapêutico Singular, ausência de ações de prevenção, etc. Tudo isso, balizado pelas constatações sobre a exiguidade do quadro de profissionais e as precárias condições de trabalho dos mesmos.

Discussões tensas e intensas demandavam dos apoiadores institucionais da região, consultores da PNH, um exercício clínico-político de inclusão do conflito, com manutenção das condições de possibilidade de análise em grupo. Um trabalho viabilizador de deslocamentos de posições e lugares dos sujeitos que, identificados maciçamente com seus serviços, colocavam-se pouco permeáveis a avaliações de conjunto do território e em estado de "guerra" particular.

Com isso, uma inflexão importante se produziu: da análise de casos passou-se à abordagem da linha de cuidado da atenção em Saúde Mental.

Da evidência de dois modelos de atenção em Saúde Mental em operação na região nasceu a disposição imediata para alinhamentos conceituais e políticos, conversas entre os CAPS, AMAS, UBSs e Hospitais, produzindo mudanças imediatas e significativas em termos de responsabilização pelos cuidados, modos de se relacionar em rede, etc. A Saúde Mental seguiu a mesma divisão em microrredes citada acima. Além disso, uma comissão composta por trabalhadores de diferentes serviços iniciou um "desenho do fluxo da atenção em Saúde Mental", produzindo constatações, questões, sugestões, propostas, etc.

O PET-Saúde Mental (que trabalha especificamente com transtornos mentais e álcool e outras drogas), parceria com a PUC-SP, teve seu início neste período, fruto do conjunto de indagações que já circulavam no território e tomou como foco a potencialização da Atenção Básica na atenção à Saúde Mental. Desenvolvendo uma pesquisa-ação (2012-2014) com a participação de professores, estudantes, profissionais e usuários da rede de atenção psicossocial, analisou os itinerários de cuidado e autocuidado em saúde mental tendo como foco duas UBSs: Silmarya Rejane Marcolino de Souza e Augusto Ayrosa Galvão. Tal análise resultou na formulação de diversos projetos nas linhas de cuidado em Saúde mental (Gestão Autônoma da Medicação) particularmente na Linha de cuidado álcool e outras drogas e na promoção de saúde junto a adolescentes e jovens que seguem hoje como projetos vigorosos na microrrede Alto da Serra ${ }^{24}$.

Ressaltaram-se daí, pontos críticos, tais como o despreparo da Atenção Básica, Pronto Socorros, AMAS e NASF para o acolhimento em Saúde Mental, falta de profissionais, desarticulação dos serviços, medicalização desenfreada, ao lado de algo mais grave ainda: a inexistência de um Projeto co-construído de Saúde Mental para o território, um Projeto que revisitasse os princípios da Reforma Psiquiátrica, da Luta Antimanicomial, levando em conta tanto o histórico dos movimentos sociais e da saúde na Freguesia do Ó, como também o contexto de experimentação da humanização. Projeto que pudesse emergir enquanto criação coletiva do e no território e que extrapolasse os limites de uma 
administração dos serviços existentes ou de criação de novos serviços.

\section{Grupo de Trabalho de Humanização - Saúde Mental (GTH-SM)}

A questão "como construir um Projeto de Saúde Mental para o território?" deu passagem para a organização de uma "força tarefa": um subgrupo de Trabalho, um GT de Saúde Mental para: i) pensar uma proposta/movimento de construção coletiva do Projeto de Saúde Mental da Freguesia do Ó, incluindo a questão da Formação em Saúde Mental para trabalhadores de toda a rede de saúde da região; ii) fazer a gestão do trabalho das microrredes de Saúde Mental do território; iii) encaminhar as deliberações relativas à questão da falta de psiquiatras, psicólogos, CAPS, etc.

O referido GT de Saúde Mental, desdobramento do GT Redes da FÓ/Brasilândia, discutiu os pressupostos de um Projeto de Saúde Mental, projeto que seria objeto de discussão e aprovação por parte dos diferentes profissionais e usuários dos espaços de gestão compartilhada existentes na região e foi atravessado pela introdução do Plano Rede de Atenção Psicossocial (RAPS) do município de São Paulo, com o qual veio a contribuir muito posteriormente através da participação de muitos dos integrantes do GTH-SM nos Coletivos em Prol de Saúde Mental, objeto de apresentação adiante.

O trabalho do GT Redes seguiu com a análise da situação da atenção às urgências e emergências, através dos analisadores desta linha de cuidado. Teve lugar outra série de encontros, inclusão efetiva de conselheiros e um redobrado esforço de aproximação dos outros serviços essenciais ao aquecimento de uma rede de atenção à saúde: Serviço de Atendimento Móvel de Urgência (SAMU), Corpo de Bombeiros, Hospitais estaduais, etc.

Dois temas insistiram com veemência: i) a necessidade de investimentos consideráveis na qualificação para o Acolhimento com Classificação de Risco (aplicável aos serviços de Urgência e Emergência) e Análise de Vulnerabilidade (comumente usado na Atenção Primária de Saúde) e ii) a necessidade de envolver a gestão central, na figura da Coordenadoria Norte de Saúde de SP, para além da Supervisão Técnica de Saúde (STS) já completamente comprometida com o processo. $\mathrm{O}$ tema aqui apontado referia-se à governabilidade dos atores envolvidos para a sustentação de um processo de articulação de sistema e de produção de saúde no território.

O envolvimento/compromisso da Coordenadoria Norte foi muito parcial e o que vingou proficuamente no território, na sequência, foi: i) um processo de formação-intervenção em acolhimento com análise de vulnerabilidade e classificação de risco envolvendo os trinta serviços da região com seus conselheiros e com participação dos estagiários do Pró-Saúde da PUC/SP também na organização; ii) a articulação dos trabalhadores, gestores e conselheiros da FÓ/Brasilândia com parcelas do movimento social organizado e da população usuária, moradora da região, expresso nas Plenária Populares de Saúde da região; iii) um processo de aproximação da equipe da STS da FÓ/Brasilândia com a equipe da ASF por meio de reuniões para discussão sobre gestão compartilhada da política de saúde para o território.

\section{Processo de formação-intervenção em acolhimento com análise de vulnerabilidade e classificação de risco para os serviços de saúde da FÓ/ Brasilândia}

Em 2013 aconteceu a primeira etapa do processo de formação intervenção em Acolhimento com Classificação de Risco e Vulnerabilidade (ACCRV), envolvendo profissionais e usuários de trinta serviços de saúde, aproximadamente 180 pessoas, sendo trinta gerentes e 150 trabalhadores e conselheiros de dezoito UBSs, quatro AMAS, uma Ambulatório Médico de Especialidades AME, um Pronto Socorro, uma Maternidade, três CAPS, um Centro de Convivência e Cooperativa, Programa Acompanhante da Pessoa com Deficiência, Programa de Acompanhante ao Idoso, um Núcleo Integrado de Reabilitação um Centro de Referência e Tratamento da AIDS um Centro de Referência em AIDS, estagiários do Pró e PET Saúde da PUC/SP, usuários etc. Foram dez oficinas presenciais, várias locais (três oficinas em cada serviço), atividades de dispersão tais como a análise de demanda espontânea das unidades/ serviços, a análise de cenário mediante cinco eixos da Atenção Primária à Saúde (acessibilidade, integralidade, longitudinalidade, coordenação do cuidado e controle social), o "trilhares na rede" (visitas entre serviços para aquecimento da rede e mapeamento dos recursos), algumas assembleias comunitárias, a preparação de terreno para a cons- 
trução de Planos de Ação para a implementação do ACCRV, as reuniões preparatórias das atividades de formação, as reuniões avaliativas, etc.

Podemos elencar como impacto: a disseminação da Diretriz do ACCRV, a discussão das Diretrizes da Política Nacional de Atenção Básica pela primeira vez em muitas unidades; a constituição de grupalidades pensantes e operantes nas unidades; integração entre trabalhadores/equipes; constituição de colegiados de gestão em unidades que não tinham; ampliação do grau de comunicação interserviços, entre trabalhadores e usuários, entre serviços da região; revisões de fluxogramas de atendimento com mudanças em processos de trabalho; problematização das "condutas protocolares"; amadurecimento de equipes (ampliação da escuta, da responsabilização pela continuidade do cuidado, conscientização sobre a Atenção Primária à Saúde como coordenadora do cuidado e sobre a existência de uma rede com a qual se pode contar); gestão compartilhada do processo ACCRV disparado, etc.

\section{Plenárias Populares de Saúde da Região Norte}

Fruto de parcerias profícuas com a Pastoral da Saúde, Supervisão Técnica de Saúde FÓ/ Brasilândia e dos anos de investimento do GTH no território, em 2012 foi organizada a primeira Plenária Popular Propositiva e Deliberativa da região. Estiveram presentes usuários, conselheiros (locais, municipais, estaduais), estagiários do Pró e Pet Saúde da PUC/SP, representantes de movimentos sociais, Fóruns, consultores da PNH, Pastoral da Saúde, Pastoral da Juventude, Trabalhadores e Gestores (de Unidades Básicas de Saúde Atendimento Médico Ambulatorial, AMA, AME, Centro Psicossocial, Centro de Cultura e Convivência, Prontos Socorros, Hospitais, Núcleos de Apoio à Saúde da Família Centro de Referência e Treinamento - DST/AIDS, Supervisão Técnica de Saúde - FÓ/Brasilândia, Centro de Referência em Saúde do Trabalhador, Supervisão de Vigilância em Saúde, Centro de Convivência e Formação, Associação de Saúde da Família Associação Paulista para o Desenvolvimento da Medicina, Programa de Atendimento ao Idoso, etc.), Universidades (PUC/ SP, Faculdade Metropolitanas Unidas FMU/SP), Liderança do Partido dos Trabalhadores na Câmara, Movimento da Saúde.

Durante três horas de roda, discutiu-se a situação da Saúde de dois territórios envolvidos: fragilidades, potencialidades, necessidades e demandas da rede, pontos programáticos de uma carta compromisso a ser discutida com a nova gestão da SMS-SP, pactuações, etc. Como resultado desse processo, no início de 2013, produziu-se um documento contendo as fragilidades, as potencialidades, as necessidades e os interesses da população da Freguesia do Ó-Brasilândia, relativos à melhoria das condições de produção da saúde na região. Tal documento foi objeto de discussão da plenária com a Coordenadoria Norte de Saúde e com o Secretário de Saúde de São Paulo.

Durante os anos de 2013 e 2014, muitos temas entraram na roda de conversa das plenárias, incluindo-se aí o tema da necessidade de formação dos usuários e conselheiros sobre modelos de atenção em Saúde. A partir desta constatação, as plenárias organizaram três seminários sobre modelos de atenção em Saúde, trabalhando o SUS, a Atenção Primária em Saúde, a diretriz do Acolhimento com Análise de Vulnerabilidade e Classificação de Risco na Atenção Básica, o tema da XV Conferência de Saúde.

As Plenárias Populares de Saúde continuaram acontecendo até 2015, com periodicidade bimensal, ampliando-se assim a potência do movimento disparado na região e nas conversas sobre a Política de Saúde - seus limites, suas potencialidades, as necessidades de ampliação e qualificação do cuidado, os modos de gestão - e imprimindo o tom de composição de forças, negociação, pactuações com o nível central, deliberações comunitárias.

\section{Grupo Gestor do Território}

A análise da fragmentação das ações macrogestoras da saúde no território propiciou, também, a organização de um espaço de encontro da Supervisão de Saúde da FÓ/Brasilândia com a Associação Saúde da Família. Este grupo encontrou-se regularmente até 2015 para compartilhar a gestão da Saúde no território. Suas funções foram de ordem macropolíticas: criação das condições de possibilidade de gestão compartilhada da Política de Saúde em implementação no território, a partir de análises de situação, elaboração de conflitos, apoio aos movimentos disparados pelos coletivos de trabalhadores e usuários da rede, proposições e definição de prioridades, etc.

\section{O fazer-coletivo como processo}




\section{vivo}

De acordo com o levantamento feito no II Encontro de Humanização/2012, havia onze Fóruns na região, além de Grupos de Trabalho e outros espaços coletivos de trabalho - Fórum dos Trabalhadores, Fórum Reabilitação, Fórum Redes, Fórum Infância e Juventude, Fórum Terceira Idade, Fórum Cultura de Paz, GTH, GTI, Grupo Gestores, expressando a potência coletiva dessa rede de saúde. Da mesma forma, assim como espaços interinstitucionais e intersetoriais, as próprias equipes dos serviços operam microrredes que necessitam também de investimento contínuo para que funcionem na articulação entre os profissionais.

Para além das articulações entre trabalhadores de distintos serviços e o investimento nos espaços interinstitucionais e intersetoriais, também as reuniões de equipe dentro dos próprios serviços são dispositivos em que prevalecem os processos grupais e coletivos ${ }^{25}$. As reuniões, quando investidas como um lugar de horizontalidade e transdisciplinaridade, podem contribuir na desburocratização e integralidade da atenção em saúde. Além disso, os espaços de reunião demonstram-se essenciais na integração e diálogo entre diferentes saberes, especialmente nas formas de composição e apoio entre profissionais da Saúde Mental e de Saúde da Família. A tomada coletiva de decisões, da mesma forma, amplia o compromisso dos profissionais com as intervenções, fortalecendo a corresponsabilidade em torno das prioridades eleitas para o trabalho. Tais práticas necessitam, no entanto, de permanente reflexão e abertura para se rever e transformar ${ }^{26}$. Ainda que a força coletiva das ações da rede de saúde da FÓ/Brasilândia se expresse na sua história e na sua prática atual, observamos que a constituição de espaços coletivos e de diálogo não é um movimento contínuo, nem tampouco estanque. Pelo contrário, a constituição desses espaços responde a demandas de fortalecimento de determinadas ações e práticas, que estão inscritas em determinados contextos e situações. E nesta perspectiva que, ao ser compreendido como dispositivo, interessou cartografar as urgências históricas que o acionaram, ao mesmo tempo reconhecer os planos instituintes e instituídos que condicionavam sua formação e dissolução.

Alguns espaços potentes, estabelecidos inicialmente, posteriormente, "enfraquecem" e vão dando lugar a outros. Há, portanto, uma experimentação de embrião da gestão coletiva e participativa ou cogestão que encontra terreno fértil em determinados contextos, sedimentando experiências aglutinadoras e de potentes encontros, ainda que muito disso se transforme em um momento posterior, em um movimento menos vivo.

O fazer-coletivo comparece, enfim, em uma dupla acepção: fala tanto de um modo de estar juntos no fazer, uma prática que é cooperada, como da própria produção do coletivo enquanto realidade produzida no tensionamento entre o plano das formas e o plano das forças e, portanto, provisório e aberto a variações ${ }^{2,3}$ como mostram outros trabalhos ${ }^{27}$.

Será que esses espaços coletivos também promovem a formação dos profissionais, no sentido de manterem vivos os processos de elaboração e problematização das concepções de saúde e de cuidado envolvidas em sua prática? Será que também podem ter a função de acolhimento, quando os profissionais veem suas angústias frente aos desafios do trabalho acolhidas de forma coletiva e podem estabelecer parcerias de trabalho conjunto?

\section{Referências}

1. Foucault M. História da sexualidade I: a vontade de saber. $17^{\mathrm{a}}$ ed. São Paulo: Graal; 2006.

2. Escossia, L da. Coletivizar. In: Fonseca TMG, Nascimento ML, Maraschin C. (orgs). Pesquisar na diferença - um abecedário. Porto Alegre: Editora Sulina; 2012. p.53-6.

3. Escossia, L da. O coletivo como plano de criação na Saúde Pública. Interface. 2009; 13(supl.1): 689-94.

4. Onocko-Campos RT, Furtado JP. Narrativas: utilização na pesquisa qualitativa em saúde. Rev. Saúde Pública. 2008; 42(6):1090-6.

5. Lourau R. Análise institucional e práticas de pesquisa. Rio de Janeiro: NAPES/ UERJ; 1993.

6. Contreiras H, Matta GC. Privatização da gestão do sistema municipal de saúde por meio de Organizações Sociais na cidade de São Paulo, Brasil: caracterização e análise da regulação. Cad. Saúde Pública [periódico na internet]. 2015 Fev [acesso em 2016 Set 02]. 31 (2): 285-97. Disponível em: http://www.scielo.br/ pdf/csp/v31n2/0102-311X-csp-31-02-00285.

7. Secretaria Municipal de Saúde de São Paulo. Implantando o PSF no município de São Paulo - conversando com os Distritos. In: Relatório Final das Oficinas de trabalho. SMSSP: 2002.

8. Secretaria Municipal de Saúde de São Paulo. Fortalecendo o Pacto entre a SMS e as instituições parceiras para consolidação do PSF no município de São Paulo. In: Relatório Final das Oficinas de trabalho. SMSSP: 2004. 
9. Andrade D, Ishida R, Jóia J, Trenche MCB. Implementação da rede de saúde na região da Freguesia do Ó e Brasilandia. In: Vicentin MCG. et al (orgs) Saúde Mental, Reabilitação e Atenção Básica: encontro entre Universidade e Serviços de Saúde: São Paulo: Editora Artgraph; 2016. p.33-52.

10. Brasil. Ministério da Saúde. Coordenação de Saúde Mental e Coordenação de Gestão da Atenção Básica. Saúde mental e atenção básica: o vínculo e o diálogo necessários. Brasília: Ministério da Saúde; 2003.

11. Brasil. Ministério da Saúde. Secretaria de Atenção à Saúde. Coordenação Geral de Saúde Mental. Saúde Mental no SUS: os centros de atenção psicossocial. Brasília: Ministério da Saúde; 2004.

12. Campos GWS. Apoio matricial e equipe de referência: uma metodologia para a gestão do trabalho interdisciplinar em saúde. Cad. Saúde Pública [periódico na internet]. 2017 Fev [acesso em 2016 Mai 6]. 23(2): 399-407. Disponível em: http://dx.doi. org/10.1590/S0102-311X2007000200016.

13. Guedes JS, Santos RMB dos, Lorenzo RV di. A Implantação do Programa de Saúde da Família (PSF) no Estado de São Paulo (1995-2002). Saúde e Sociedade [periódico na internet]. 2011 Out/Dez. [acesso em 2016 Ago 6] 20(4): 875-83. Disponível em http://dx.doi.org/10.1590/S0104-12902011000400006.

14. Campos GWS, Figueiredo MD, Júnior NP, Castro CP de. A aplicação da metodologia Paideia no apoio institucional, no apoio matricial e na clínica ampliada. Interface [periódico na internet]. 2014 Ago [acesso em 2016 Mai 7]. 18(1): [aproximadamente 8 p.]. Disponível em: http://www.scielo.br/scielo.php?script=sci arttext\&pid=S1414-32832014000500983\&lang=pt.

15. Vicentin MCG, Almeida IS de, Saes D. O que os itinerários de saúde mental nos ensinam sobre o processo de trabalho em saúde: encontros entre pesquisa e assistência. In: Vicentin MCG, Trenche MCB, Kahhale EP, Almeida IS de (orgs) et al. Saúde Mental, Reabilitação e Atenção Básica: encontro entre Universidade e Serviços de Saúde. São Paulo: Artgraph; 2016. p.32-52.

16. Castro CP de, Oliveira MM de, Campos GWS. Apoio Matricial no SUS Campinas: análise da consolidação de uma prática interprofissional na rede de saúde. Ciênc. Saúde Colet. [periódico na internet]. 2016 Maio [acesso em 2016 Jun 6] 21(5): [aproximadamente 9 p.]. Disponível em: http:// www.scielosp.org/scielo.php?script $=$ sci arttext\&pid=S1413$81232016000501625 \& \operatorname{lng}=$ pt\&tlng $=$ pt.

17. Lancetti A. Saúde mental nas entranhas da metrópole. In: Lancetti A (org). Saúde mental e saúde da família. $2^{\mathrm{a}}$ Ed. São Paulo: Editora Hucitec; 2001. p. 11-52. (Série Saúde e Loucura, 7).

18. Other MB, Ayres JRCM. Necessidades de saúde da pessoa com deficiência: a perspectiva dos sujeitos por meio de histórias de vida. Interface [periódico na internet]. 2012 Mar [acesso em 2016 Jun 15] 16(40): 219-33. Disponível em: http://www.scielo. br/pdf/icse/v16n40/aop1212.pdf

19. Pavan C. Relatório Analítico da implementação do Plano de Trabalho 2012 do GTH da Região da Freguesia do Ó-Brasilândia/SP, 2012 (Mimeo).

20. Martins CP, Luzio CA. Política Humaniza SUS: ancorar um navio no espaço. Interface [periódico na internet]. $2016 \mathrm{Abr}$. [acesso em 2016 Jun 20]; 21 (60): [aproximadamente 10 p.]. Disponível em: http://www.scielo.br/pdf/icse/2016nahead/18075762-icse-1807-576220150614.pdf.
21. Pavan C, Trajano ARC. Apoio institucional e a experiência da Política Nacional de Humanização (PNH) na Freguesia do Ó, Brasilândia, São Paulo, Brasil. Interface [periódico na internet]. 2014 Ago, [acesso em 2016 Jun 15]; 18(1): [aproximadamente 9 p.]. Disponível em: http://www.scielo.br/scielo.php?script=sci arttext\&pid=S1414-32832014000501027\&lng=pt\&nrm=iso $\&$ tlng $=$ pt.

22. Martins CP, Luzio CA. Experimentações no apoio a partir das apostas da Política Nacional de Humanização - Humaniza SUS. Interface [periódico na Internet]. 2014 Ago [acesso em 2016 Jun 16]; 18(1): 1099-106. Disponível em: http://www.scielo. br/scielo.php?pid=S1414-32832014000501099\&script=sci abstract\&tlng=PT.

23. Navarro LM, Pena RS. A Política Nacional de Humanização como estratégia de produção coletiva das práticas em saúde. Revista de Psicologia da UNESP [periódico na internet]. 2013 Maio. [acesso em 2016 Jun 23] 12(1): [aproximadamente 7 p.] . Disponível em: http://pepsic.bvsalud.org/scielo.php?script=sci arttext\&pid=S1984-90442013000100007.

24. Vicentin MCG, Almeida IS, Saes D. O que os itinerários de saúde mental nos ensinam sobre o processo de trabalho em saúde: encontros entre pesquisa e assistência. In: Vicentin MCG, Trenche MCB, Kahhale EP, Almeida IS de (orgs) et al. Saúde Mental, Reabilitação e Atenção Básica: encontro entre Universidade e Serviços de Saúde. São Paulo: Artgraph; 2016. p.32-52.

25. Santa Cruz ML et al. Reunião de equipe: uma reflexão sobre sua importância enquanto estratégia diferencial na gestão coletiva no Programa de Saúde da Família (PSF). Psic. Rev. 2008; 17 (1 e 2): 161-83.

\section{Silva KL, Sena RS, Akerman M, Belga SMM, Rodrigues AT.}

Intersetorialidade, determinantes socioambientais e promoção da saúde. Ciênc. Saúde Colet. [periódico na internet] 2014 Ago [acesso em 2016 Jun 9] 19(11): [aproximadamente 6 p.]. Disponível em: http://www.scielosp.org/scielo.php?script=sci arttext\&pid=S1413-81232014001104361.

27. Ferro LF, Silva EC da, Zimmermann AB, Castanharo RCT, Oliveira FRL de. Interdisciplinaridade e intersetorialidade na Estratégia Saúde da Família e no Núcleo de Apoio à Saúde da Família: potencialidades e desafios. Mundo Saúde [periódico na internet]. 2014 Mar [acesso em 2016 Jun 6]; 38(2): 129-38. Disponível em: http://bvsms.saude.gov.br/bvs/artigos/mundo_ saude/interdisciplinariedade_intersetorialidade_estrategia saude_familia.pdf. 